
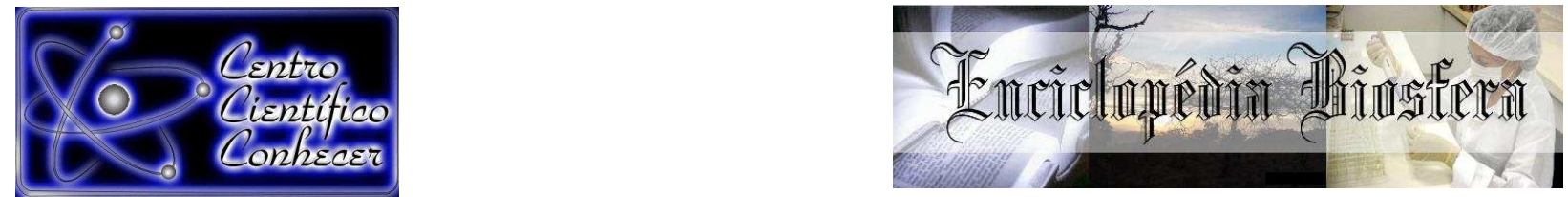

\title{
REGENERAÇÃO IN VITRO DE Cattleya nobilior LndI (ORCHIDACEAE) UTILIZANDO DIFERENTES CONCENTRAÇÕES DE SACAROSE E BENZILADENINA
}

Camila Filipin Chaves ${ }^{1}$, Andréia Izabel Mikosvki ${ }^{2}$, Nayara Tayane da Silva ${ }^{3}$, Solange Kimie Ikeda Castrillon ${ }^{4}$, Maurecilne Lemes da Silva Carvalho ${ }^{5}$

${ }^{1}$ Professora Departamento de Ciências Biológicas, Universidade do Estado de Mato Grosso/UNEMAT, (camilinhafilipin@gmail.com),Tangará da Serra, MT, Brasil.

${ }^{24}$ Graduandas em Ciências Biológicas, Universidade do Estado de Mato Grosso Tangará da Serra, MT, Brasil.

${ }^{3}$ Professora Doutora do Departamento de Ciências Biológicas, Universidade do Estado de Mato Grosso/UNEMAT, Cáceres, MT, Brasil.

${ }^{5}$ Professora Doutora do Departamento de Ciências Biológicas, Universidade do Estado de Mato Grosso/UNEMAT, Tangará da Serra, MT, Brasil.

Recebido em: 08/09/2015 - Aprovado em: 14/11/2015 - Publicado em: 01/12/2015 DOI: http://dx.doi.org/10.18677/Enciclopedia_Biosfera_2015_029

\begin{abstract}
RESUMO
O trabalho teve como objetivo regenerar in vitro a espécie Cattleya nobilior em função de concentrações de sacarose combinados com a citocinina Benziladenina. Plantas de $\pm 3 \mathrm{~cm}$ de comprimento foram utilizadas como fonte de explantes. As plantas foram cultivadas em frascos de cultivo no meio de $\mathrm{MS}, 100 \mathrm{mg} \mathrm{L}^{-1}$ de mioinositol, 20 e $30 \mathrm{~g} \mathrm{~L}^{-1}$ de sacarose combinados com 1,0, 1,5 e 2,0 $\mathrm{mg} \mathrm{L}^{-1}$ Benziladenina (BA) e gelificados com ágar a $8,0 \mathrm{~g} \mathrm{~L}^{-1}$ e $\mathrm{pH}$ ajustado para 5,7 \pm 0,1. Após 30 e 60 dias de cultivo observou-se diferença entre os tratamentos, onde a concentração de $20 \mathrm{~g} \mathrm{~L}^{-1}$ de sacarose $+1,5 \mathrm{mg} \mathrm{L}^{-1}$ de BA (T2) apresentou o maior número de brotos produzidos, com 10 e 30, respectivamente. A concentração de 20 $\mathrm{g} \mathrm{L}^{-1}+1,0 \mathrm{mg} \mathrm{L}^{-1}$ de BA (T1) de sacarose foi a que apresentou o menor número de brotações, 2 brotos com 30 dias e com 60 dias o desenvolvimento de 7 brotos.
\end{abstract}

PALAVRAS-CHAVE: Brotos, Cultivo in vitro, Orquídeas.

\section{REGENERATION IN VITRO Cattleya nobilior LindI. (ORCHIDACEAE) USING DIFFERENT CONCENTRATION OF SUCROSE AND BENZYLADENINE}

\begin{abstract}
The work aimed to regenerate in vitro species Cattleya nobilior in function of sucrose concentrations combined with the cytokinin Benziladenina. Plants of $\pm 3 \mathrm{~cm}$ lenght were used as source of explants. The plants were grown in culture flasks in the middle of $\mathrm{MS}, 100 \mathrm{mgL}^{-1}$ of myoinositol, 20 and $30 \mathrm{~g} \mathrm{~L}^{-1}$ of sucrose combined with $1.0,1.5$ and $2.0 \mathrm{mg} \mathrm{L}^{-1}$ Benzyladenine (BA) and gelled with agar at $8.0 \mathrm{~g} \mathrm{~L}^{-1}$ and $\mathrm{pH}$ adjusted to $5.7 \pm 0.1$. After 30 and 60 days of cultivation, it is noticed the difference between the treatments, where the concentration of $20 \mathrm{~g} \mathrm{~L}^{-1}$ sucrose $+1.5 \mathrm{mg} \mathrm{L}^{-1} \mathrm{BA}$ (T2) presented the higher number of buds produced 10 and 22 , respectively. The
\end{abstract}


concentration of $20 \mathrm{~g} \mathrm{~L}^{-1}+1.0 \mathrm{mg} \mathrm{L}^{-1} \mathrm{BA}(\mathrm{T} 1)$ of sucrose was the one which presented the smallest number of buds, 2 buds with 30 days and with 60 days developed 7 buds.

KEYWORDS: Buds, In vitro cultivation, Orchid.

\section{INTRODUÇÃO}

A família Orchidaceae compreende uma das maiores famílias do grupo das angiospermas, apresentando cerca de 35.000 espécies distribuídas em 1.800 gêneros (PEREIRA, 2010). No Brasil, segundo último levantamento, ocorrem 235 gêneros e 2.428 espécies nativas; sendo 66 gêneros e 1.632 espécies endêmicas do país (BARROS et al. 2013).

As orquídeas apresentam relevante importância econômica, devido às suas características ornamentais, com flores de tamanhos, cores e formas variadas, sendo comercializadas em todo o mundo e retiradas de forma excessiva da natureza o que leva muitas espécies a riscos de extinção (SOARES, et al., 2011; SCHNEIDERS et al., 2012.).

Plantas do gênero Cattleya são intensamente comercializadas. O gênero é composto por 45 espécies distribuídas nas zonas tropicais desde o México até países como Paraguai e Brasil, e dentre elas destacam-se a espécie Cattleya nobilior (BIANCHETTI, 2007). Espécie encontrada no bioma cerrado, de substrato epífita ou rupícula, que vegeta em matas secas (BARROS et al. 2013). Esta espécie apresenta coluna encoberta pelos lobos laterais do labelo, pseudobulbos sob duas ou algumas vezes três folhas, floração primaveril e flores de tamanho grande (MENEZES, 2004; SANTOS, 2011).

A espécie $C$. nobilior se destaca entre as orquídeas por possuir uma ampla capacidade de recombinação genética, estrutura, beleza e durabilidade de suas flores, essas características fazem com que ocorra uma intensa exploração, o que, de forma conjunta com a degradação de seus habitats têm resultado na erosão genética desta espécie (SILVA et al., 2009). A regeneração natural da Cattleya é dificultada pelo seu crescimento lento devido ao metabolismo ácido das crassuláceas e das interações mutualísticas que apresentam com insetos e microorganismos quer para a polinização ou para germinação (Roberts e Dixon 2008; SUZUKI et al., 2010).

Nas duas últimas décadas, as técnicas de cultivo in vitro de orquídeas têm sido utilizadas para propagação clonal de forma rápida, obtendo-se plantas mais resistentes e para o estudo de aspectos fisiológicos relacionados ao crescimento e desenvolvimento e como uma alternativa de conservação ex situ (FERREIRA \& SUZUKI, 2008; ARFUX et al. 2015).

No Brasil, esta técnica vem sendo utilizada com o intuito de aumentar a produção de mudas com qualidade genética tendo como consequência a redução de custos (CORDEIRO, et al., 2011) e o manuseio de grande número de indivíduos em espaço reduzido e sob condições assépticas (VILA, 2014).Vários compostos são utilizados para a otimização de protocolos de germinação, sendo a sacarose a fonte de carboidrato mais utilizado na micropropagação, pois possui alta solubilidade e rápida metabolização, sendo o mais transportado e armazenado pela maioria dos vegetais (PASQUAL, 2001). Este composto atua como fator determinante na promoção de crescimento e é dependente do tipo de explante.

A síntese de sacarose ocorre em vários órgãos e tecidos, sendo a principal fonte de carbono utilizada na maior parte dos processos biossintéticos como a 
respiração e são precursores para a biossíntese de componentes estruturais e funcionais como oligossacarídeos, aminoácidos e outras moléculas necessárias para o crescimento das plantas (CASTRO et al., 2005).O suprimento exógeno de açúcar pode ampliar as reservas de amido e sacarose nas plantas micropropagadas, favorecer a aclimatização ex vitro e acelerar as adaptações fisiológicas (CALDAS et al. 1998, HAZARIKA, 2003).

$\mathrm{Na}$ cultura de tecidos, a adição de reguladores de crescimento ao meio nutritivo é de extrema importância, pois reproduz o que ocorre naturalmente na planta, às combinações entre essas substâncias propiciam melhor crescimento e desenvolvimento do explante (REZENDE et al., 2010). A espécie e o tipo de explante respondem de forma diferente à ação dos diversos tipos de reguladores de crescimento utilizados no cultivo in vitro. Dentre os principais tipos de reguladores com efeito sobre a micropropagação, estão as citocininas e auxinas, cujas concentrações são fatores determinantes para o desenvolvimento da planta sob condições in vitro (LIMA et al., 2002). Um dos reguladores responsáveis pela indução de brotações é a Benziladenina (BA), uma citocinina da classe de hormônios vegetais ou reguladores de crescimento derivados da adenina, que induzem a divisão celular (PIERIK, 1990).

O trabalho teve como objetivo regenerar in vitro a espécie Cattleya nobilior em função de concentrações de sacarose combinados com a citocinina Benziladenina.

\section{MATERIAL E MÉTODOS}

Plantas de C. nobilior de aproximadamente $\pm 3 \mathrm{~cm}$ de comprimento (Figura 1B) foram utilizadas como fonte de explantes (Figura 1A). As plantas foram inoculadas em frascos de cultivo na presença de meio semi sólido de $M S$ (MURASHIGE \& SKOOG, 1962), $100 \mathrm{mgL}^{-1}$ de mio-inositol, 20 e $30 \mathrm{~g} \mathrm{~L}^{-1}$ de sacarose combinados com 1,0, 1,5 e 2,0 $\mathrm{mg} \mathrm{L}^{-1}$ de Benziladenina (BA) e gelificados com ágar a $8,0 \mathrm{~g} \mathrm{~L}^{-1}$. O pH foi ajustado para $5,7 \pm 0,1$ e autoclavado por 15 minutos $\left(121^{\circ} \mathrm{C}\right.$ e $1,1 \mathrm{~atm}$ de pressão). Foram adicionados $60 \mathrm{~mL}$ de meio em cada frasco e vedados com filme de PVC. Os explantes foram cultivados em sala de cultura e mantidos sob irradiância de $36 \mu \mathrm{mol} \mathrm{m} \mathrm{m}^{-2} \mathrm{~s}^{-1}$, fotoperíodo de 16 horas de luz e 8 horas de escuro e temperatura de $25 \pm 2^{\circ} \mathrm{C}$. Os tratamentos foram com $20 \mathrm{~g} \mathrm{~L}^{-1}$ de sacarose $+1,0 \mathrm{mg}$ $\mathrm{L}^{-1} \mathrm{BA}(\mathrm{T} 1), 20 \mathrm{~g} \mathrm{~L}^{-1}$ de sacarose $+1,5 \mathrm{mg} \mathrm{L}^{-1} \mathrm{BA}(\mathrm{T} 2), 20 \mathrm{~g} \mathrm{~L}^{-1}$ de sacarose $+2,0 \mathrm{mg}$ $\mathrm{L}^{-1} \mathrm{BA}$ (T3), $30 \mathrm{~g} \mathrm{~L}^{-1}$ de sacarose $+1,0 \mathrm{mg} \mathrm{L}^{-1} \mathrm{BA}$ T4), $30 \mathrm{~g} \mathrm{~L}^{-1}$ de sacarose $+1,5 \mathrm{BA}$ $\mathrm{mg} \mathrm{L}^{-1}$ (T5),) $30 \mathrm{~g} \mathrm{~L}^{-1}$ de sacarose $+2,0 \mathrm{mg} \mathrm{L}^{-1} \mathrm{BA}$ (T6).

As avaliações foram realizadas aos 30 dias e 60 dias de cultivo in vitro. Sendo que aos 30 dias avaliou o número de brotos e aos 60 dias o número de brotos e o comprimento das brotações. O delineamento experimental utilizado foi 0 inteiramente casualizado, com 6 tratamentos, 3 repetições e 7 explantes por repetição. Os dados foram submetidos ao teste de variância e as médias comparadas pelo teste de Tukey a $5 \%$ de significância, utilizando-se o software SISVAR 5.3 (FERREIRA, 2003).

\section{RESULTADOS E DISCUSSÃO}

Após 30 dias de cultivo in vitro observou-se diferença entre os tratamentos, onde a concentração de $20 \mathrm{~g} \mathrm{~L}^{-1}$ de sacarose e $1,5 \mathrm{mg} \mathrm{L}^{-1}$ de BA (T2) produziu maior número de brotações com média de 10 brotos (Figura 1D) (TABELA 1). A concentração de $20 \mathrm{~g} \mathrm{~L}^{-1}$ de sacarose com 1,0 mg L${ }^{-1}$ de BA foi a que apresentou 0 menor número de brotações com média de 2 brotos (T1) (Figura 1C). Aos 30 e 60 
dias de cultivo in vitro independente das concentrações de sacarose, observou que o aumento na concentração de BA reduziu a produção de brotos em $C$. nobilior.

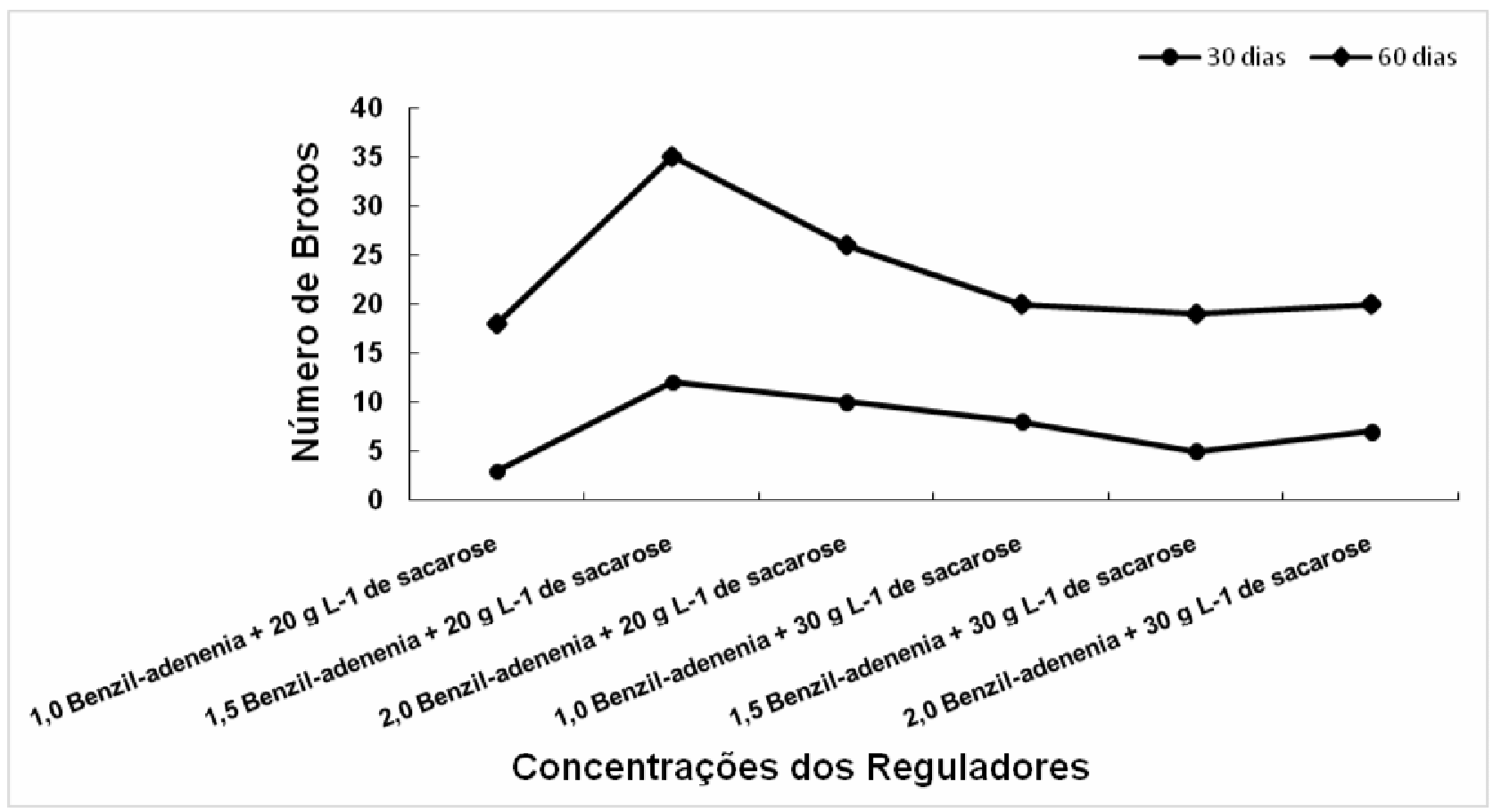

FIGURA 1. Média do número de brotos produzidos em função das concentrações de sacarose e da citocinina Benziladenina (BA).

Os demais tratamentos não diferiram estatisticamente entre si. Segundo FIOR (2007), as citocininas são a classe de fitoreguladores mais utilizadas na fase de multiplicação, devido ao seu efeito na quebra de dominância apical e na indução de proliferação de gemas axilares. No cultivo in vitro de $C$. violaceae a utilização de 20 a $30 \mathrm{gL}^{-1}$ de sacarose foram os que melhor responderam na germinação e no desenvolvimento (GALDIANO JUNIOR et al., 2013). Os autores enfatizam que a utilização de sacarose diferentes destas concentrações reduzem o crescimento das plântulas desta espécie de orquídea. Aos 30 dias de cultivo pode-se observar o desenvolvimento de primórdios radiculares (Figuras 1C).

Já aos 60 dias de cultivo foi possível verificar aumento no número de brotações (TABELA 1), principalmente no T2 $\left(20 \mathrm{~g} \mathrm{~L}^{-1}\right.$ de sacarose $+1,5 \mathrm{mg} \mathrm{L}^{-1} \mathrm{de}$ $\mathrm{BA})$ teve maior número médio de brotos produzidos com 30 brotações e as plantas cultivadas no (T1) com $20 \mathrm{~g} \mathrm{~L}^{-1}$ de sacarose $+1,0 \mathrm{mg} \mathrm{L}^{-1}$ de BA produziram apenas 7 brotos. Estes resultados demonstram que para a regeneração in vitro de $C$. nobilior a concentração de $20 \mathrm{~g} \mathrm{~L}^{-1}$ de sacarose, combinado com 1,5 $\mathrm{mg} \mathrm{L}^{-1}$ de BA, induz uma melhor resposta no desenvolvimento de brotações adventícias nesta espécie de orquídea (Figura 2 E e F).

Em relação ao comprimento dos brotos aos 60 dias de cultivo (TABELA 1), não ocorreu diferenças estatísticas entre os tratamentos. No entanto, pode-se observar que no tratamento (T2) o resultado foi similar quando se utilizou $30 \mathrm{~g} \mathrm{~L}^{-1}$ de sacarose + e 1,0 mg L $\mathrm{m}^{-1}$ de BA (T4) e $30 \mathrm{~g} \mathrm{~L}^{-1}$ de sacarose + e $1,5 \mathrm{mg} \mathrm{L}^{-1}$ de BA (T5) e o meio de cultura quando suplementado com sacarose auxilia na manutenção e 
conservação das células e na aclimatização de plantas cultivadas sob condições in vitro (GALDIANO JÚNIOR, 2013).
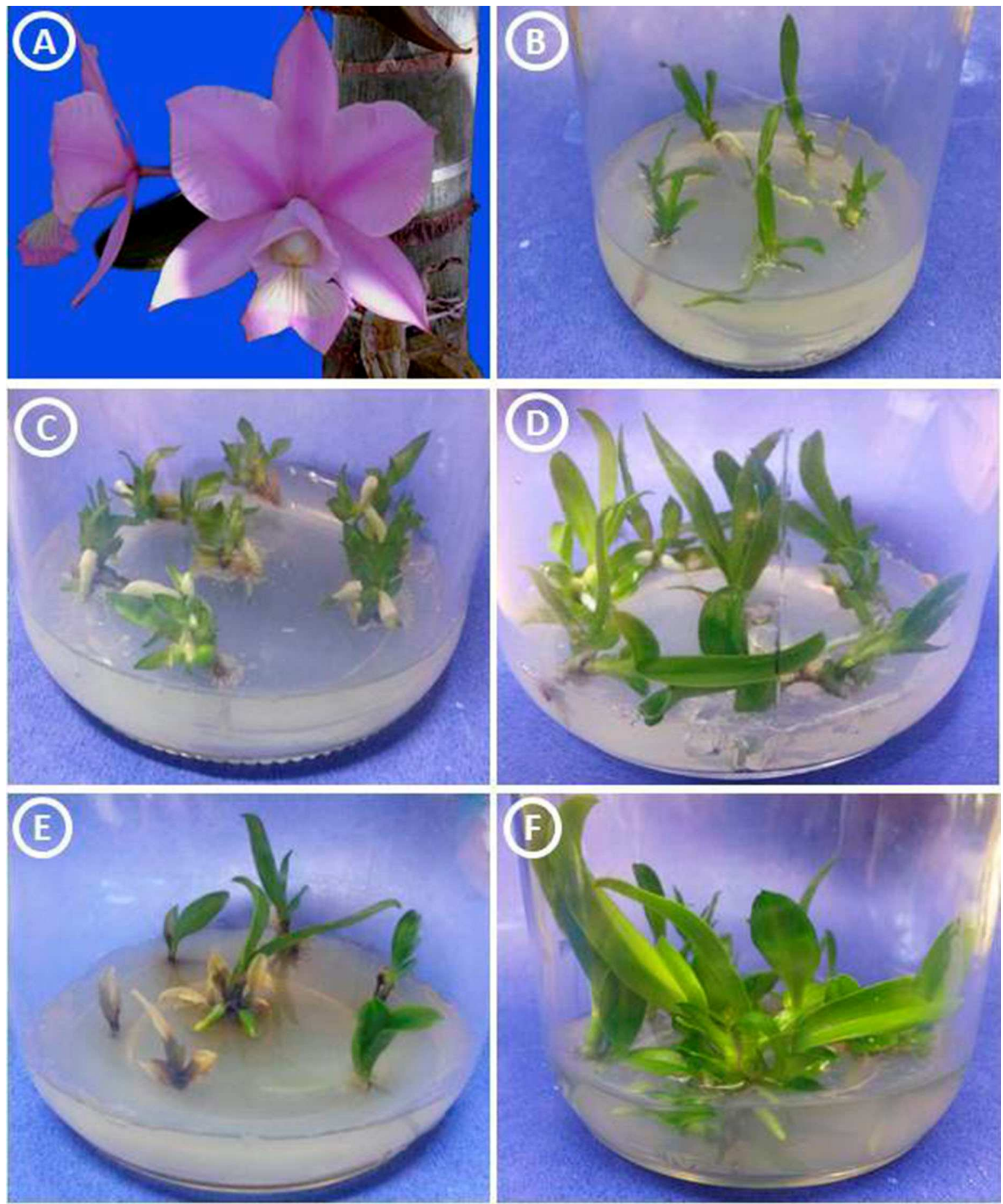

FIGURA 2: Flor e produção de brotos cultivados in vitro de Cattleya nobilior: A) Flor. B) Plantas utilizadas como fonte de explantes. C) Plantas aos 30 dias de cultivo no tratamento com $20 \mathrm{~g} \mathrm{~L}^{-1}$ de sacarose $+1,0 \mathrm{mg} \mathrm{L}^{-1}$ de Benziladenenia. D) Plantas aos 30 dias de cultivo no tratamento com $20 \mathrm{~g} \mathrm{~L}^{-1}$ de sacarose $+1,5 \mathrm{mg} \mathrm{L}^{-1}$ de Benziladenenia. E) Plantas aos 60 dias de cultivo no tratamento com $20 \mathrm{~g} \mathrm{~L}^{-1} \mathrm{de}$ sacarose $+1,0 \mathrm{mg} \mathrm{L}^{-1}$ de Benziladenenia. F) Plantas aos 60 dias de cultivo no tratamento com $20 \mathrm{~g} \mathrm{~L}^{-1}$ de sacarose $+1,5 \mathrm{mg} \mathrm{L}^{-1}$ de Benziladenenia. 
TABELA 1. Efeito de concentrações de sacarose e de Benziladenina na regeneração in vitro de C.nobilior.

\begin{tabular}{cccc}
\hline $\begin{array}{c}\text { Concentrações } \\
\text { de sacarose }\left(\mathrm{g} \mathrm{L}^{-1}\right) \\
\text { e BA }\left(\mathrm{mg} \mathrm{L}^{-1}\right)\end{array}$ & $\begin{array}{c}\mathrm{N}^{\circ} \text { de brotos } \\
\text { aos } 30 \text { dias }\end{array}$ & $\begin{array}{c}\mathrm{N}^{\circ} \text { de brotos } \\
\text { aos } 60 \text { dias }\end{array}$ & $\begin{array}{c}\text { Comprimento das plântulas em } \\
\mathrm{cm} 60 \text { dias }\end{array}$ \\
\hline 20 sac. $+1,0 \mathrm{BA}$ & $2 \mathrm{a}$ & $7 \mathrm{a}$ & $1,4 \mathrm{a}$ \\
20 sac. $+1,5 \mathrm{BA}$ & $10 \mathrm{~b}$ & $22 \mathrm{~b}$ & $2,0 \mathrm{a}$ \\
20 sac. $+2,0 \mathrm{BA}$ & $9 \mathrm{ab}$ & $15 \mathrm{ab}$ & $1,9 \mathrm{a}$ \\
30 sac. $+1,0 \mathrm{BA}$ & $7 \mathrm{ab}$ & $12 \mathrm{ab}$ & $2,0 \mathrm{a}$ \\
30 sac. $+1,5 \mathrm{BA}$ & $5 \mathrm{ab}$ & $13 \mathrm{ab}$ & $2,0 \mathrm{a}$ \\
30 sac. $+2,0 \mathrm{BA}$ & $6 \mathrm{ab}$ & $12 \mathrm{ab}$ & $1,8 \mathrm{a}$
\end{tabular}

Médias seguidas pela mesma letra minúscula nas colunas não diferem significativamente pelo teste de Tukey a $5 \%$ de probabilidade. Sac. $=$ sacarose e BA $=$ Benziladenina.

A adição de sacarose ao meio de cultura mostra-se necessária para grande parte das espécies micropropagadas, pois possui alta solubilização e rápida metabolização, sendo transportado e armazenado pelos tecidos vegetais. A síntese de sacarose ocorre em vários órgãos e tecidos, tornando-se a principal fonte de carbono para processos biossintéticos da planta, sendo as concentrações de 2 a $4 \%$ as mais utilizadas. Estas concentrações permitem a manutenção dos processos metabólicos ativos da planta e favorecem o seu crescimento, porém abaixo dessa faixa ocorre clorose nas folhas e acima dela, excessivo potencial osmótico provocando a deterioração da cultura (OLIVEIRA et al., 2011; FERNANDES, 2012).

Segundo CHAVES et al., (2005), o BA tem demonstrado eficiência no processo de multiplicação de partes aéreas e na indução de gemas adventícias, no entanto em algumas cultivares, elevadas concentrações desse regulador aumentam a taxa de proliferação e diminuem o tamanho dos brotos

Os carboidratos adicionados ao meio nutritivo afetam significativamente 0 crescimento e as respostas fisiológicas das plantas in vitro, atuando como fonte de energia e de carbono podendo atuar também como regulador osmótico do meio de cultura (FLORES et al. 2013).

A obtenção de plantas regeneradas in vitro de C.nobilior poderá ser uma alternativa para o plantio em áreas de matas de cerrado, tendo em vista a exploração extrativista desta importante espécie ornamental.

\section{CONCLUSÕES}

Obteve-se brotações em todas as concentrações de reguladores utilizadas, sendo o tratamento $20 \mathrm{~g} \mathrm{~L}^{-1}$ de sacarose $+1,5 \mathrm{mg} \mathrm{L}^{-1}$ de BA o que apresentou a maior média de produção de brotos in vitro na espécie de Cattleya nobilior, podendo ser utilizado na produção de plantas desta espécie. 


\section{REFERÊNCIAS}

ARFUX, C. R. B.; MENEGATI, C. F.; Silva, R. M. RONDON, J. N.; GABRIEL, V.; COSTA, F. A.; CARVALHO, C. M. E.; SOUZA, P. F.; SILVA, C. B. Cultivo in vitro de Salvia hispanica L. Revista Eletrônica em Gestão, Educação e Tecnologia Ambiental. Santa Maria, v. 19, n.2, 2015.

BARROS, F.; VINHOS, F.; RODRIQUES V.T.; BARBERENA, F.F.V.A.; FRAGA, C.N.; PESSOA, E.M.; FORSTER, W.; MENINI NETO, L.; FURTADO, S.G.; NARDY, C.; AZEVEDO, C.O.; GUIMARÃES, L.R.S. Orchidaceae. Lista de Espécies da Flora do Brasil. Jardim Botânico do Rio de Janeiro. v. 3, 2013.

BIANCHETTI, L.B. Cattleya nobilior. Heringeriana. Brasília, v.1, n.1, p. 9-10, 2007.

CALDAS, L.S.; HARIDASAN, P.; FERREIRA, M.E. Meios Nutritivos. In: TORRES, A.C.; CALDAS, L.S., BUSO, J.A. (Eds.). Cultura de tecidos e transformação genética de plantas. v.1. Embrapa, Brasília, Distrito Federal.p. 87-132, 1998.

CASTRO, P. R. C.; KLUGE, R. A.; PERES, L. E. P. Manual de fisiologia vegetal: teoria e prática. Piracicaba: Editora Agronômica Ceres, p. 650, 2005.

CHAVES, A.C.; SCHUCH, M. W.; FACHINELLO, J. C. ORIENTAÇÃO DO EXPLANTE, BAP E MEIO DE CULTURA NA MULTIPLICAÇÃO IN VITRO DOS PORTA-ENXERTOS DE PRUNUS OKINAWA E MR. S 1/8. Plant Cell Culture Micropropagation. Lavras, MG, v. 1, n. 1, p. 47-52, 2005.

CORDEIRO, G. M.; MORAES, C. P.; MASSARO, R.; CUNHA, T. Desenvolvimento in vitrode Cattleya methystoglossa Lindley X (Cattleya dupreana X Laelia purpurata Lindley) em diferentes meios de cultura. Revista Científica Eletrônica de Agronomia. Garça, v. 18, n. 1, p. 22-28, 2011.

FERNANDES, D. A. Efeito de diferentes concentrações de sacarose e tipos de vedação no cultivo in vitro e no enraizamento ex vitro de teca (TectonagrandisL.f.). Dissertação de Mestrado no programa de Ciências Florestais e Ambientais. Universidade Federal De Mato Grosso. Cuiabá. p. 2, 2012.

FERREIRA W. M \& SUZUKI R. M. O cultivo in vitro de orquídeas como alternativa para a preservação de espécies nativas ameaçadas de extinção. In: Loiola MIB, Baseia IG \& Lichston JE (Org.) Atualidades, desafios e perspectiva da botânica no Brasil. Natal, Imagem Gráfica, p.67-68, 2008.

FERREIRA, D.F. Análises estatísticas por meio do Sisvar para Windows versão 4.0. In: 45a Reunião Anual da Região Brasileira da Sociedade internacional de Biometria. UFSCar, São Carlos, SP, ANAIS, p. 255-258, 2003.

FIOR, C. Propagação de plantas in vitro: teoria à prática. Arquivos Clonoagro. 2007.

FLORES, R.; ULIANA, S. C.; PIMENTEL, N.; GARLET, T. M. B. Sacarose e sorbitol na conservação in vitro de Pfaffia tuberosa (Spreng.) Hicken (Amaranthaceae). Biotecnologia e Biodiversidade.v. 4, n.3, p. 192-199,2013.

GALDIANO JÚNIOR, R.F.; MANTOVANI, C.; CASSANO, A. O.; LEMOS, E. G. M. Desenvolvimento inicial e crescimento in vitro de Cattleya violácea (Kunth) Rolfe em 
diferentes concentrações de sacarose. Acta Amazonica. v. 43, n. 2, p. 127-134, 2013.

GALDIANO JÚNIOR, R.F.; MANTOVANI, C.; FARIA, R. T.; LEMOS, E. G. M. Concentrações de sacarose no desenvolvimento in vitro e na aclimatização de Cattleya loddigesii Lindley. Semina: Ciências Agrárias, Londrina - PR.v. 34, n. 2, p. 583-592, 2013.

HAZARIKA, B.N. Acclimatization of tissue-cultured plants. Current Science, v. 85, n.12, p. 1704-1712, 2003.

LIMA, G. P. P.; BARSALOBRES, C.; PIZA, I. M. T.; CEREDA, M. P. Efeito do bap e ana e atividade da peroxidase em mandioca (Manihot esculenta crantz cvmcol 22) cultivada in vitro. Revista Brasileira de Agrociência, v. 8, n. 2, p. 107-110, 2002.

MENEZES, L. C. Orquídeas/Orchids: Orquídeas do Planalto Central Brasileiro. Brasília, Edições IBAMA, 2004.

MURASHIGE, T.; SKOOG, F. A. Revised medium for rapid growth and bioassays with tobacco tissue cultures. Physiologia Plantarum, v. 15, n.3, p. 473-497, 1962.

OLIVEIRA, M. B., ALVES, K. A., LIMA, M. H. M., ANDRADE, L. F., IZZO NETO, A., LONDE, L. N., SOUZA, A. S. Efeito de concentrações de sacarose e de meio de cultura (8s) sobre a taxa de crescimento da mandioca variedade bgm 0043 (riqueza) conservadas in vitro. In: Embrapa Mandioca e Fruticultura - Artigo em anais de congresso (ALICE). In: CONGRESSO BRASILEIRO DE MELHORAMENTO DE PLANTAS, Búzios. Panorama atual e perspectivas do melhoramento de plantas. 2011.

PASQUAL, M. Introdução: Fundamentos básicos. Lavras: UFLA/ FAEPE, p. 97, 2001.

PEREIRA, J.A.F.; MELO, G.M.; ULISSES, C.b. Anatomia foliar do Dendrobium anosmum (Orchidaceae) durante a fase de aclimatização. X JORNADA DE ENSINO, PESQUISA E EXTENSÃO - JEPEX- UFRPE. Recife. 2010.

PIERIK, R.L.M. Cultivo in vitro de las plantas superiores. Madrid: MundiPrensa, 1990.

PORTO, J. N. L.; SILVA, K. L. F. Análise morfológica do desenvolvimento inicial in vitro de Cattleya nobilior rchb. F. (Orchidaceae). 10 Seminário de Iniciação Científica da UFT. 2014.

REZENDE, J. C.; CARVALHO, C. H. S.; SANTOS, A. C. R.; PASQUAL M.; MENDES, A. N. G. Influência de auxina e citocinina no desenvolvimento de embriões somáticos de Coffea arábica L. Plant Cell Culture Micropropagation. Lavras, v.7, n.1, p. 1-8, 2011

ROBERTS, D. L.; DIXON, K. W. Orchids. Current Biology. v. 18, p. 325-329, 2008.

SANTOS, T. M. Eventos antigos de especiação híbrida no grupo bifoliado do gênero Cattleya Lindl. (Orchidaceae) inferidos a partir de uma filogenia 
baseada em 16 regiões de DNA nuclear e plastidial. Dissertação de Mestrado em Botânica. Universidade Estadual de Feira de Santana. Bahia. 2011.

SCHNEIDERS, D., PESCADOR, R., BOOZ, M. R., SUZUKI, R.M. Germinação, crescimento e desenvolvimento invitro de orquídeas (Cattleya spp., Orchidaceae). Ceres, Viçosa, v. 59, n.2,2012.

SILVA, E. F.; VILLA, F.; PASQUAL, M. Meio de cultura knudson modificado utilizado no cultivo in vitro de um hibrido de orquídea. Scientia Agraria, v. 10, n. 4,p. 267274, 2009.

SOARES, J. D. R.; PASQUAL, M.; RODRIGUES, F. A.; VILLA F.; ARAUJO, A. G. Fontes de silício na micropropagação de orquídea do grupo Cattleya. Acta Scientiarum Agronomy. Maringá, v. 33, n. 3, p. 503-507, 2011.

SUZUKI, R.M.; ALMEIDA, V.; PESCADOR, R; FERREIRA, W. M. Germinação e crescimento in vitro de Cattleya bicolor Lindley (Orchidaceae). Hoehnea, São Paulo, v.37, n.4, 2010.

VILLA, F.; PASQUAL, M.; SILVA, E. F. Micropropagação de híbridos de orquídea em meio Knudson com adição de vitaminas do meio $\mathrm{ms}$, benzilaminopurina e carvão ativado. Semina, Londrina, v. 35, n. 2, p. 683-694, 2014. 